\title{
Hands-on Activities and Their Influence on Students' Interest
}

\author{
Nina Holstermann • Dietmar Grube • Susanne Bögeholz
}

Published online: 12 November 2009

(C) The Author(s) 2009. This article is published with open access at Springerlink.com

\begin{abstract}
This study investigates the influence of hands-on activities on students' interest. We researched whether students with experience in specific hands-on activities show higher interest in these activities than students without experience. Furthermore, the relationship between the quality of the hands-on experience and interest in the respective activity was examined. In total, 28 typical hands-on activities of biology education were considered. The activities were divided into the categories experimentation, dissection, work with microscopes, and classification. A total of 141 students from the 11th grade completed questionnaires on interest in the hands-on activities, their experience with each activity, and the quality of the respective experience. Students' interest in experimenting, working with microscopes, dissecting and classifying tends to benefit from performing hands-on activities. However, findings indicated that the performance of various hands-on activities can influence students' interest differently. For seven hands-on activities, we identified a positive effect of hands-on experience on interest, while in one case, practical work appeared to have influenced students' interest negatively. However, for most hands-on activities, no effect of experience on interest was found. The quality of hands-on experiences showed positive correlations with interest in the respective hands-on activities. Therefore, this paper argues in favour of designing biology lessons that allow for experiences with hands-on activities that also interest students. Our findings underline the necessity of investigating the effects of various hands-on activities in a differentiated manner.
\end{abstract}

Keywords Classify · Dissection · Experiment · Hands-on activity · Interest · Microscope · Quality of experience

N. Holstermann $(\bowtie) \cdot$ S. Bögeholz

Department of Biology Education, University of Göttingen, Waldweg 26, 37073 Göttingen, Germany e-mail: nholste1@gwdg.de

D. Grube

Educational and Developmental Psychology, University of Göttingen, Waldweg 26, 37073 Göttingen, Germany 


\section{Introduction}

In many Western developed countries, a decline in students' interest in science and in the recruitment of students to science studies has been noticed (EU 2004). This decline in interest applies not only for 'hard' science subjects, such as physics and chemistry; students' interest in biology also tends to decrease from primary to secondary school (Löwe 1992). The perceived lack of relevance of the science curriculum is seen as one reason for adolescents' low interest and their lack of motivation to pursue science in higher education (Sjøberg and Schreiner 2005). Furthermore, being a scientist may have become a less attractive career aspiration for young people in modern societies (Sjøberg and Schreiner 2005). In order to counteract the existing decline in interest and to motivate adolescents to pursue science in higher education, it is important to investigate situational factors that might spark or hold students' interest in science topics as well as their interest in working scientifically. The current investigation aims to contribute to this important issue by comparing the effects of various hands-on activities on students' interest. In particular, two research questions are addressed in this paper. The first addresses whether performing hands-on activities in biology classes can influence students' interest in these activities, while the second focuses on the relationship between the quality of hands-on experiences and interest in the respective activities.

In general, conducting hands-on activities in biology classes; for example, in field or laboratory settings, is widely recommended by educational authorities like the National Association of Biology Teachers (NABT 2005). Hofstein and Lunetta (2003) claimed that there was a failure in science education to examine the effects of various school science experiences on students' attitudes. They argued that investigating the influence of experience on adolescents' attitudes would be important for science education, since experiences that promote positive attitudes could have very beneficial effects on students' interest and their learning. However, what do we know nowadays about interest and in particular about the influence of hands-on activities on students' interest?

Interest is often defined as a content-specific person-object relationship that emerges from an individual's interaction with the environment (Krapp 2005; Schiefele 1991). Interest is an important variable in the school context, as it can influence students' levels of learning, their academic performance and the quality of their learning experience (cf. Hidi and Renninger 2006; Schiefele 1991; Schiefele et al. 1993). Practical work, or so-called hands-on experience, is one situational factor that is often assumed to evoke students' interest and to motivate them to learn science (Bergin 1999).

Hands-on in general means learning by experience. Students handle scientific instruments and manipulate the objects they are studying (Rutherford 1993). It is assumed that working in a hands-on way provides a more realistic and exciting experience of the content (Franklin and Peat 2005; Nott and Wellington 1996). Most empirical studies provide evidence for the assumption that conducting hands-on activities leads to positive motivational outcomes. For instance, Middleton (1995) asked teachers and students to distinguish what they believe makes mathematics classes motivating. Both groups referred, besides other factors, to hands-on aspects as facilitating motivation. Similar results have been found for biology classes. Vogt et al. (1999) investigated how interesting specific phases of the biology lesson were perceived to be by students. Phases that contained topics of relevance for students or practical work, for instance conducting experiments or working with microscopes, were rated as highly positive. Similarly, Renner et al. (1985) interviewed students about their feelings regarding learning activities like laboratory work. They identified laboratory work as being 'interesting' as compared to other more 'boring' 
instructional formats like watching films or listening to the teacher. Thompson and Soyibo (2002) presented students with two different conditions within their chemistry classes. The experimental group was taught electrolysis for nine lessons by a mixture of lecture, teacher demonstration, class discussion and practical work in small groups. In the control group, the practical work was substituted by teacher demonstrations. After the treatment, the experimental group showed more positive attitudes towards chemistry, measured by indicators such as enjoyment of chemistry and interest in chemistry inquiry, than the control group. Ato and Wilkinson (1986) compared students from schools with a high level of science equipment usage to those from schools with low science equipment usage. The former group showed higher leisure interest in science as well as more positive attitudes towards scientific inquiry and towards scientists. No difference was found between the two groups regarding their enjoyment of science and science lessons, their attitudes towards science practical work and their career interest in science. However, there is also evidence that adolescents may be over-challenged when autonomous problem-solving is required during hands-on activities. Especially students who are not used to open laboratory work were found to be low in confidence regarding aspects of practical work that require analysis and critical thinking (cf. Haigh 1993).

What appear to be still lacking in science education are studies investigating the effects of various school science experiences on students' attitudes. The current investigation contributes to this issue by examining how specific hands-on experiences influence students' interest in these activities. Since most empirical studies indicate that practical work is beneficial for students' motivation, we hypothesised that in general, students with experience in hands-on activities will show higher interest in these activities than students without experience. However, most of the previous studies focused on practical work in general and did not look for differences between particular hands-on activities. This constitutes a shortcoming in research, since there is a large amount of diversity in hands-on activities. Different activities make various demands on students. For instance, practical work can differ with regard to the level or type of inquiry involved and students' involvement in planning the activity (cf. Lumpe and Oliver 1991). Hands-on activities can also vary in terms of time allowed for them, teachers' organisational skills, or the social and emotional climate of the class (Gardner and Gauld 1990). In order to give consideration to the diversity of hands-on activities, we specifically looked at individual hands-on activities in order to detect possible differences between them. A particular focus was placed on four categories of hands-on activities that are typically conducted in biology lessons, namely experimenting, conducting dissections, working with microscopes, and classifying creatures.

Our second research question focused on the relationship between the quality of students' hands-on experience and their reported interest in the activity. Gardner and Gauld (1990) argue that doing practical work does not, in itself, foster scientific attitudes. Rather, the quality of students' experiences during practical work is decisive (Gardner and Gauld 1990). The quality of experience is assumed to be a subjective experience of constitutional and environmental characteristics in terms of dimensions such as affect, activation, cognitive efficiency and motivation (Moneta and Csikszentmihalyi 1996; Schiefele 1991). The quality of experience during task completion is an important factor for the development of students' intrinsic motivation (Krapp 2005). Interest development will occur if a person experiences his or her actual engagement on the basis of cognitive-rational and emotional evaluations in a positive way (Krapp 2005). Therefore, interest will be strengthened when a person experiences a learning activity as enjoyable, pleasant, stimulating and important. On the other hand, repeated negative experience might also influence individual interests; for instance when students feel sad, passive or lonely or even fail a task (Schiefele 1991; Todt 
1995). Underlining this assumption, empirical studies found negative correlations between negative emotions (e.g. hopelessness) and study interest, while positive emotions such as enjoyment correlated positively with students' interest and intrinsic motivation (Pekrun et al. 2002; Schiefele 1991). In line with these empirical findings and the theoretical assumptions, we expected interest in the activity to be higher the more positively the hands-on activity was perceived by students. Again, we specifically looked at individual hands-on activities from the four categories in order to detect possible differences between them.

\section{Method}

Participants and Procedure

The sample of this cross-sectional study consisted of 141 grammar school students of the 11th grade $\left(M_{\text {age }}=16.4, S D=0.57 ; 48 \%\right.$ male). Participants were recruited from 14 classes of five grammar schools in the North of Germany. Within their regular biology education classes, half of the students in each class were selected randomly and completed a questionnaire on their interest in various hands-on activities, their experience with each hands-on activity and the quality of the respective experience. At the same time, the remaining adolescents filled out another questionnaire for research purposes, which was of no relevance for the current study.

Instruments

Since an object of interest can be defined by the content and the activities involved (cf. Gardner 1985; Hoffmann 2002), we conceptualised interest in a two-dimensional way: Following Hoffmann (2002), hands-on activities were systematically combined with academically relevant domains. Typical domains of secondary school biology education were included, namely cytology, botany, zoology, human biology and ecology. Within these domains, we focused on categories of hands-on activities which are typically conducted in biology education classes, namely experimenting, dissecting, working with microscopes and classifying creatures. However, for some combinations of domain and category it was not possible to create a reasonable item, for instance for the domain 'human biology' with the category 'classifying'. 'To carry out experiments with plants (e.g. on factors affecting germination and growth...' was a typical item that belonged to the domain 'botany' and the category 'conducting experiments'. For each of these examples of biology practice, students rated their interest, their experience and the quality of their experience: Participants estimated on a four-point Likert scale whether the particular activity was interesting for them ('...is interesting for me'; $0=$ disagree, $1=$ partially agree, $2=$ mostly agree, $3=$ agree). In addition, they marked for every item their experience with the particular activity ('I have never done ... '; 0 = agreement, 1 = disagreement). Finally, only those students with experience in a specific hands-on activity were asked to rate the quality of their experience with the respective hands-on activity on a four-point Likert scale ('I have already done .... I experienced it as'; 0 = very negative, $1=$ negative, 2 = positive, 3 = very positive). Originally, 47 hands-on activities were developed following the above-described procedure of combining domains with categories of hands-on activities. Since test statistics are more robust if samples of a similar size are compared, and as our intention was to analyse 'typical' hands-on activities of biology education, only those activities were considered for analyses with which more than $25 \%$ and less than $75 \%$ of the adolescents had indicated having experience. However, none of the activities investigated had been experienced by 
more than $75 \%$ of the students. Our final 28 examples of biology practices were allocated to the categories experimenting (nine items), dissecting (3), working with microscopes (8) and classifying creatures (8).

\section{Data Analysis}

To investigate whether performing a hands-on activity had influenced students' interest in this activity, we compared the degree of interest between students with experience in a specific activity and students without such experience by means of $t$-tests. If a $t$-test shows a significantly higher interest for students with experience in a specific hands-on activity, this may indicate that the experience of hands-on activities has positively influenced their interest. However, an influence of interest on experience would be equally consistent with this finding. For example, students who are interested in an activity might be more likely to seek out situations in which they have the opportunity to perform that activity. For the school context, this interpretation can be mostly ruled out. Interests of individual students do not usually influence whether and which hands-on activities are performed at school. Both interested and less interested students carry out the same hands-on activities. Therefore, we assumed a unidirectional influence of experience in a specific activity on interest in the respective activity.

However, differences in interest between students with and without experiences could alternatively be based on other 'common' factors: For instance, a dedicated teacher may provide students with both higher degrees of interest and more occasions to perform activities. Since common factors should rather exert their impact on interest in a broader range of hands-on activities, we controlled for such factors by conducting an analysis of covariance (ANCOVA) considering the overall interest score (= mean of all interest ratings of a subject) as a covariate.

To investigate the relationship between quality of experience and interest, bivariate correlations were calculated between the reported quality of a specific hands-on experience and students' interest in this activity.

\section{Results}

The four tables provided in the appendix show the findings on the item level differentiated for the categories experimentation (Table 2), dissection (Table 3), microscopy (Table 4) and classification (Table 5). Each table contains data about how many students indicated experience with a specific hands-on activity and about the level of mean interest in this activity for students with and without experience, respectively. In addition, the results of $t$-tests, ANCOVAs and correlation analyses are provided for every item.

\section{Relationship Between Experience and Interest}

Experimentation $T$-tests indicated a positive influence of experience on interest for two of nine items on experimentation (see Table 2 in the appendix). Students who had carried out experiments on detection of photosynthesis products and on osmotic reactions indicated more interest in these activities compared to students without experience. The results of the covariance analysis supported the notion of a direct influence of experience on interest in these contexts. However, the mean effect size of all nine items on experimentation (cf. Table 1) indicated that students' interest in experimentation did not considerably increase through hands-on activities in general (cf. Cohen 1992). The standard deviation of the effect size pointed to large differences between the effects of individual activities on interest. 
Dissection The results of the $t$-tests regarding dissections revealed a significant difference in interest between students with and without experience for one of three activities. Adolescents who had already dissected pig organs (see Table 3) showed higher interest in this activity compared to adolescents without experience. Again, the results of the covariance analysis supported the results of the $t$-tests. The mean effect size of the three items (cf. Table 1) indicated a small effect between experience in dissecting and interest in dissecting (Cohen 1992).

Microscopy With regard to microscopy, $t$-tests showed significant differences for three of eight items (see Table 4). Students who had looked at cross sections of leaves and single parts of plants, e.g. stomata, reported higher interest in these activities than students who had not done this before. In addition, students who had analysed oral mucosa cells under the microscope showed less interest in this activity compared to those without experience. Covariance analysis confirmed the relationship between experience and interest for the items on mucous membrane and cross sections. However, when the covariate was considered for the item on stomata, the significant difference in interest between students with and without experience disappeared. In this case, differences in interest between the groups with and without experience could not be interpreted in terms of influences of particular experience on interest. A mean effect size of $d=.09$ (cf. Table 1) indicated that there was no general effect of experience with microscopes on interest in examining something under the microscope (Cohen 1992). The standard deviation suggested huge differences between the effects of individual activities on interest.

Classification T-tests indicated a positive influence of experience on students' interest for two of eight items on classification. Students who had experience with classifying butterflies and had developed classification keys for plants reported higher interest in these activities (see Table 5). The covariance analysis confirmed these results for both items. The mean effect size for all items of this category (cf. Table 1) indicated a small effect (Cohen 1992). Regarding the activities given in our questionnaire, there was a general tendency for experience with classification to influence students' interest in classification positively.

In sum, the positive influence of hands-on activities on students' interest cannot be generalised to every activity. However, Fig. 1 shows the mean interest in experimenting, dissecting, working with microscopes and classifying for students with and without experience in comparison. Students' interest in these categories of hands-on activities seems to benefit from performing hands-on activities.

\section{Relationship Between Quality of Hands-on Experience and Interest}

The findings concerning the relationship between the perceived quality of hands-on experience and interest are presented in Tables 2, 3, 4 and 5. For the items on

Table 1 Mean effect size and standard deviation with regard to the influence of experience on interest for experimentation, dissection, microscopy and classification

\begin{tabular}{lcr}
\hline Category & $d$ & $S D d$ \\
\hline Experimentation (nine items) & .16 & .28 \\
Dissection (3) & .24 & .21 \\
Microscopy (8) & .09 & .33 \\
Classification (8) & .21 & .26 \\
\hline
\end{tabular}




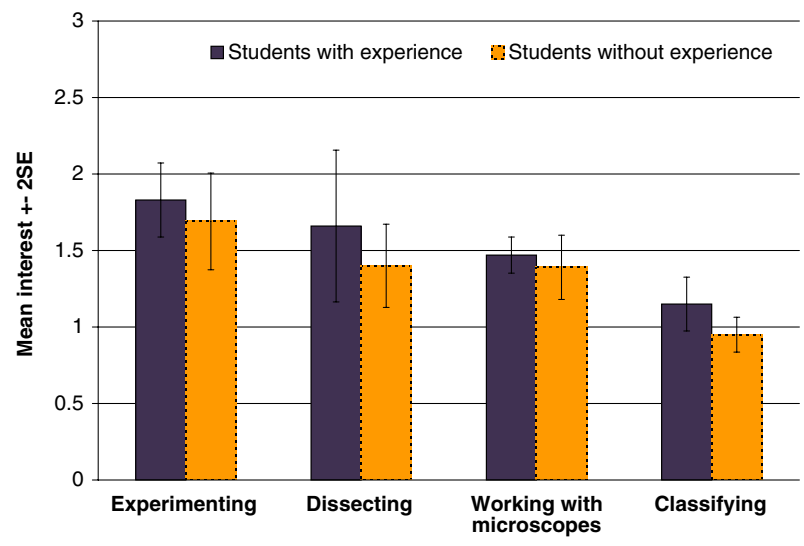

Fig. 1 Mean interest in experimenting, dissecting, working with microscopes and classifying for students with and without experience

experimentation, the correlation coefficients between the quality of experience and the reported interest ranged from $r=.44$ to $r=.84(p<.01)$. Regarding the items on dissection, the coefficients lay between $r=.61$ and $r=.88(p<.01)$. Similarly, the correlation coefficients for the items on examining something under the microscope ranged between $r=.53$ and $r=.79$. All correlations for this hands-on activity appeared to be significant $(p<.01)$. Correlation analysis between the quality of experience and interest relating to classifying creatures showed values between $r=.56$ to $r=.72(p<.01)$. In sum, the more positively adolescents had experienced experimenting, conducting dissections, working with microscopes and classifying creatures, the more interest they reported in these activities.

\section{Discussion and Implications}

This study was designed to investigate whether experience with hands-on activities can influence students' interest in these activities. To explore possible differences between particular hands-on activities, we used concrete examples of biology practices. In general, we had hypothesised that students with hands-on experience were likely to report higher interest in the respective activity than students without experience. In line with our expectation, for seven specific hands-on activities we found a positive influence of experience on students' interest in the respective activity. However, our findings appeared to be more ambiguous than expected. In most cases (for 20 items), we did not detect any significant differences in interest between adolescents with experience and those without. In one case, we even found a negative effect of practical work on students' interest. Therefore, our findings underline the importance of looking more closely at the diversity of experiments, dissections, microscopies and classifications. For instance, experimentation did not in general promote students' interest, but it seems that there are certain experiments that have the potential to do so. Although the positive influence of hands-on activities on students' interest cannot be generalised to every activity, our findings indicate that interest in a hands-on activity seems to benefit from performing the activity in a considerable number of cases (cf. Fig. 1). Moreover, the mean effect sizes of the four categories all appeared to be positive, even though they showed at most a small effect of hands-on experience on students' interest according to Cohen's (1992) classification $\left(d_{\text {experiment }}=.16\right.$; $d_{\text {dissect }}=.24 ; d_{\text {microscopy }}=.09 ; d_{\text {classify }}=.21$ ). While mean effect sizes of the categories showed 
a relatively small range (see above), the differences in effect sizes of particular activities within each category appeared to be of importance $\left(d_{\text {experiment }}:-.23-.67 ; d_{\text {dissect }}: .08-.47\right.$; $d_{\text {microscopy: }}-.34-.54 ; d_{\text {classify: }}-.01-.70$ ).

However, what do those activities that influenced students' interest positively have in common? It is striking that many of those activities that promoted interest dealt with plants; for instance developing a classification key for plants, detecting starch in leaves or looking at stomata under the microscope. Since it is known that students of the age range under study are less interested in plants than in, for instance, human biology (e.g. Holstermann and Bögeholz 2007), this finding seems surprising at first glance. However, looking at the level of interest of students without experience, we see that inexperienced adolescents indeed show less interest for activities dealing with plants; for example, looking at stomata under the microscope, than for activities dealing with human beings; for example, using the microscope to look at mucous membrane of the mouth. By contrast, students with experience estimated the microscopy of both objects to be of similar interest for them. The differing level of knowledge might be a possible explanation of this finding. Inexperienced students do not really know the activity and can therefore only estimate how interesting this activity or topic is for them. On the other hand, experienced students can make an informed judgement about their interests, since they know that both activities are alike. Additionally, it might be easier to raise students' level of interest if they are less interested in a particular hands-on activity before conducting it than if they are already highly interested in the activity.

Our second research question dealt with the relationship between the quality of experience and interest in the respective activity. Findings from the correlation analysis between the quality of hands-on experience and interest showed that for each hands-on activity, students' level of interest was higher the more positively the hands-on activity had been perceived. These findings support the theoretical position that the quality of experiences is essential for interest development (cf. Todt 1995). However, what factors lead hands-on activities to be perceived as positive or negative? This question can be answered by analysing the intrinsic quality of a specific hands-on activity. The extended model of learning motivation provides a theoretical framework by distinguishing consequence-related incentives and activity-specific incentives. While consequencerelated incentives refer to future events that are expected to happen when the action is finished successfully, activity-specific incentives refer to the (emotional) experiences while performing an activity regardless of its consequences (cf. Rheinberg et al. 2000). Activity-specific incentives are assumed to influence the quality and the level of learning motivation. They are inherent to an activity and lead this activity to be perceived positively or negatively by a person (Rheinberg et al. 2000). Therefore, the concept of activity-specific incentives can be used to explain the intrinsic quality of a particular hands-on activity. As an example, in a follow-up study, we investigated the activityspecific incentives of dissecting pig organs, since our findings had indicated a high potential of this activity to spark students' interest. A total of 122 university and secondary school students $\left(M_{\text {age }}=20.6, S D=4.1 ; 27 \%\right.$ male $)$ completed an open-ended questionnaire about the activity-specific incentives of dissecting. After participants had completed the dissection of a pig's heart or lung, they were asked what they had liked in particular about dissecting and what they had not liked about the activity. Since multiple incentives could be specified by each participant, a total of 473 statements was obtained, with 316 positive and 157 negative activity-specific incentives. Two researchers categorised students' statements independently from each other, and subsequently revised the category system together until they reached a consensus. For instance, students 
reported that they liked hands-on aspects of dissecting like touching $\left(n=15^{1}\right)$ or cutting $(n=32)$. However, they also reported minds-on aspects of dissections. For instance, they liked to recognise structures $(n=12)$, to learn something $(n=14)$ and to understand the underlying mechanisms $(n=11)$ while working on the organ. Considering such activity-specific incentives of hands-on activities, teachers might be able to design practical biology lessons that spark students' interest in hands-on activities. For dissections, this could mean that at least every student should have the chance - if he or she wishes - to touch the object and cut with a scalpel by him or herself. Additionally, it seems to be beneficial for students' motivation during dissection to combine hands-on aspects with minds-on aspects.

In conclusion, our findings suggest that - although there are differences - many hands-on activities offer the potential to positively influence students' interests in the activities. As we examined concrete examples of biology practices, teachers can derive detailed information from our study regarding how particular activities on average affect students' interest. By providing the opportunity to conduct a particular hands-on activity, teachers may influence students' interests in the activity positively (cf. Bergin 1999). Findings from our study can also inform discussions on how science curricula might integrate hands-on activities in order to meet the interests of learners. In particular, those hands-on activities that were identified as significantly raising students' interest should be considered in biology classes. By contrast, a decrease in interest through experience does not imply, for instance, that using the microscope to look at mucous membrane should no longer be applied in schools. Rather, it would be important to evaluate ways in which the microscopy of mucous membrane might be made an interesting activity that is positively experienced by the students. For instance, feelings of rejection or disgust with regard to mucous membrane might work as intrapersonal barriers for students' interest development (cf. Bixler and Floyd 1999). By creating a scientific atmosphere and allowing representative prior experiences, a reduction in negative feelings may be reached even before conducting the activity itself (cf. Gropengiesser and Gropengiesser 1985). However, promoting interest cannot constitute the only reason why students should perform hands-on activities. Examining the mucous membrane under the microscope also leads to a more realistic view of the mucous membrane and helps students to imagine what human cells look like.

By considering the positive mean effect sizes of the four hands-on categories, a small but positive influence of experience in dissecting and classifying on students' interest in these categories may be assumed. Since our findings point to the crucial role of the quality of experience, teachers should create biology lessons that allow experiences with hands-on activities which are experienced positively by the students. The investigation of activityspecific incentives gives an indication of relevant factors. In general, educators should provide an adequate level of difficulty to challenge students without overburdening them (cf. Haigh 1993). The high relevance of working scientifically ought to be illustrated to adolescents by conducting hands-on activities by themselves (cf. Sjøberg and Schreiner 2005). The use of particular hands-on activities to attract students' interest in practical work might be a first step to counteract the decline of students' interest in biology and to motivate adolescents to pursue biology in higher education (cf. EU 2004; Löwe 1992).

Acknowledgement This research was supported by a grant of the German Research Foundation (DFG). We gratefully acknowledge the research assistance provided by Silke Vogel and Eva-Maria von den Benken.

Open Access This article is distributed under the terms of the Creative Commons Attribution Noncommercial License which permits any noncommercial use, distribution, and reproduction in any medium, provided the original author(s) and source are credited.

\footnotetext{
${ }^{1}$ Number of students who reported an activity-specific incentive of the respective category.
} 


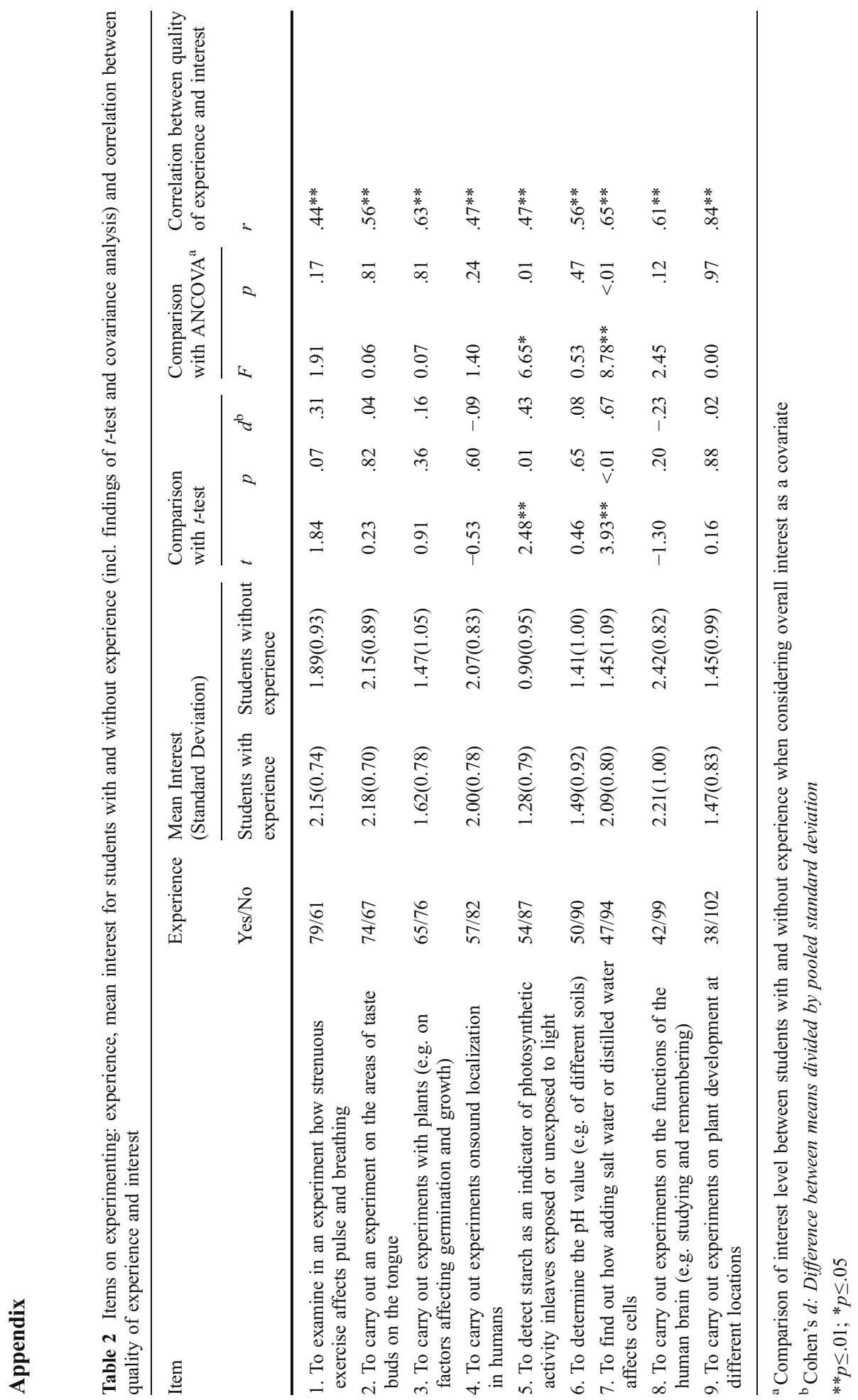




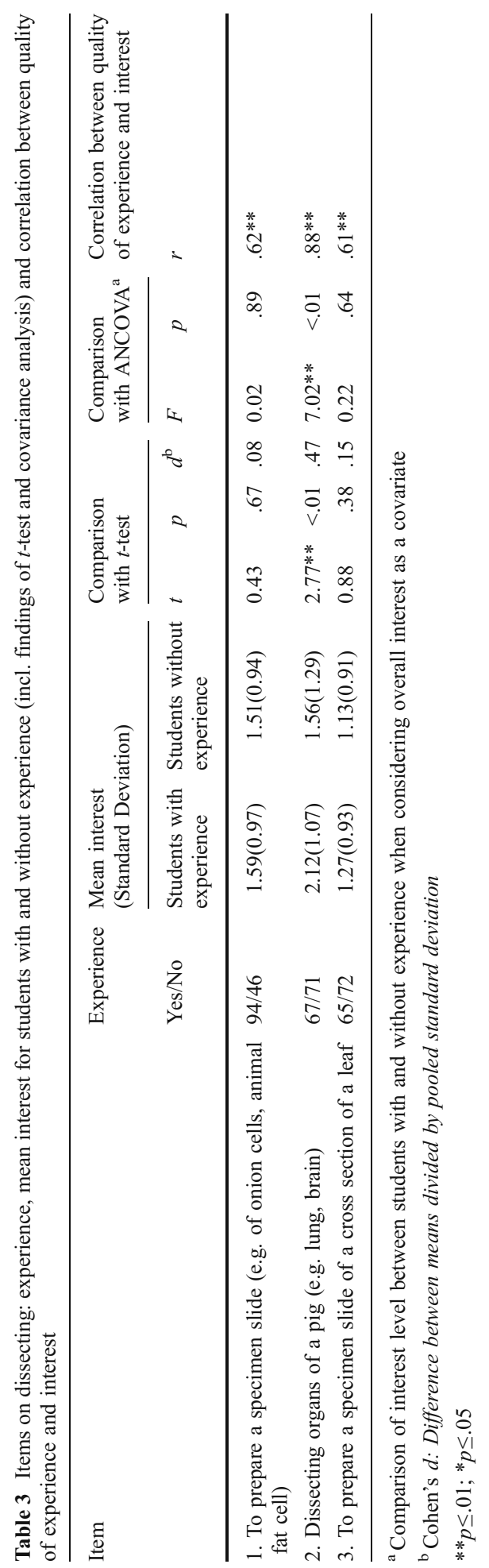




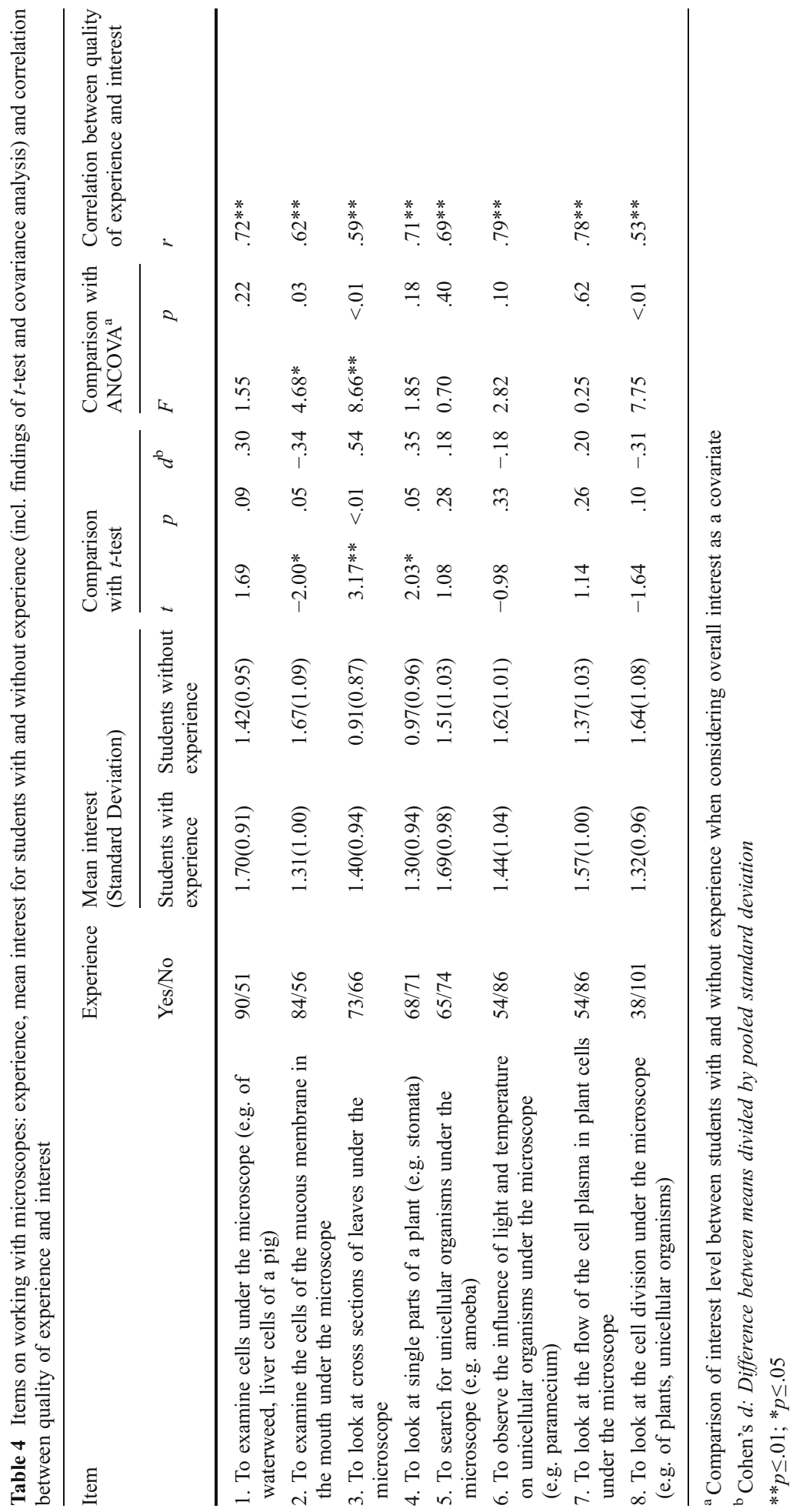




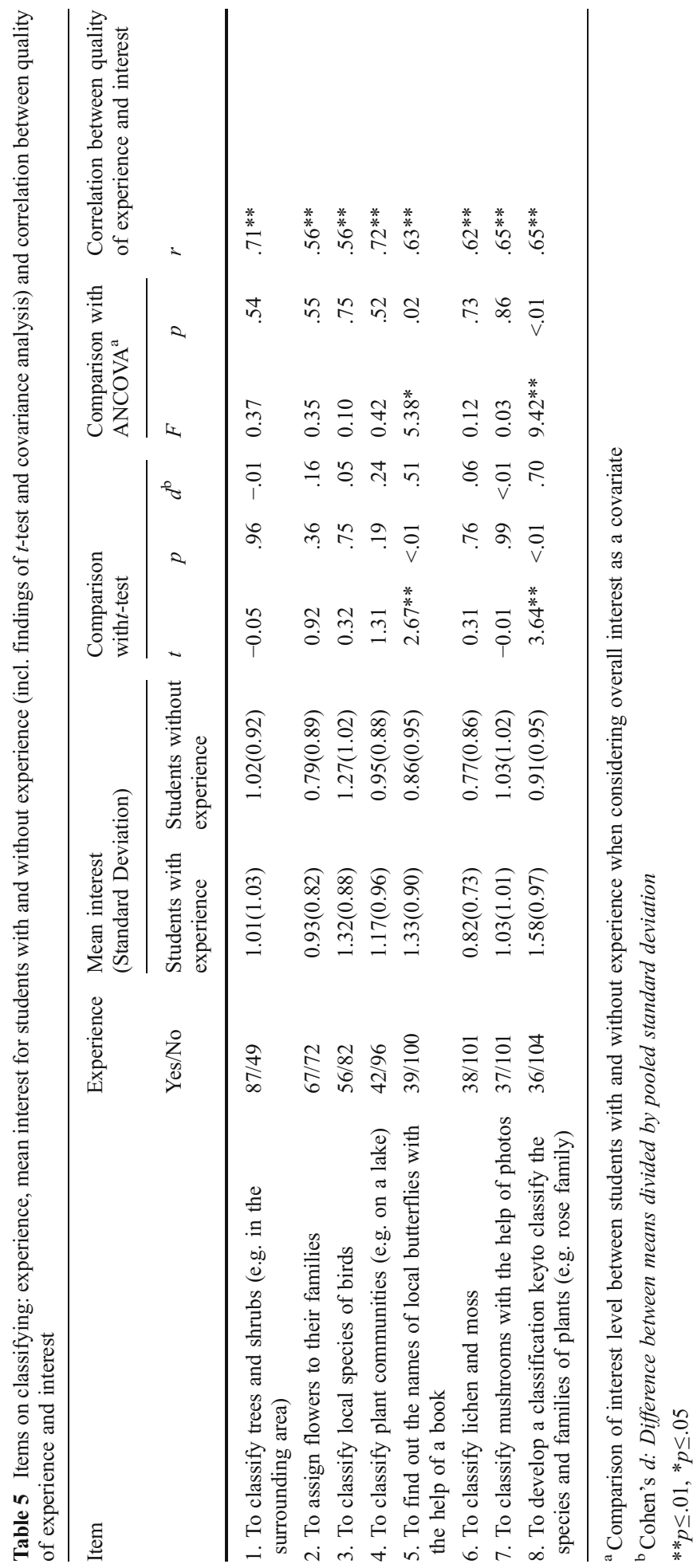




\section{References}

Ato, T., \& Wilkinson, W. J. (1986). Relationships between the availability and use of science equipment and attitudes to both science and sources of scientific information in Benue State, Nigeria. Research in Science \& Technological Education, 4, 19-28.

Bergin, D. A. (1999). Influences on classroom interest. Educational Psychologist, 34, 87-98.

Bixler, R. D., \& Floyd, M. F. (1999). Hands on or hands off? Disgust sensitivity and preference for environmental activities. Journal of Environmental Education, 30, 4-11.

Cohen, J. (1992). A power primer. Psychological Bulletin, 112, 155-159.

EU (2004). Europe needs more scientists. Report by the high level group on increasing human resources for science and technology in Europe. Retrieved June 26, 2009, from http://ec.europa.eu/research/ conferences/2004/sciprof/pdf/final en.pdf

Franklin, S., \& Peat, M. (2005). Virtual versus real: an argument for maintaining diversity in the learning environment. International Journal of Continuing Engineering Education and Life Long Learning, 15, 67-78.

Gardner, P. (1985). Students' attitudes to science and technology: an international overview. In M. Lehrke, L. Hoffmann \& P. Gardner (Eds.), Interests in science and technology education (pp. 15-34). Kiel: Institute for Science Education (IPN).

Gardner, P., \& Gauld, C. (1990). Labwork and students' attitudes. In E. Hegarty-Hazel (Ed.), The student laboratory and the science curriculum (pp. 132-156). London: Routledge.

Gropengiesser, H., \& Gropengiesser, I. (1985). Ekel im Biologieunterricht [Disgust in biology class]. Unterricht Biologie, 9, 40-42.

Haigh, M. A. (1993). "Hands on-minds on": introducing openness into senior biology practical work. Research in Science Education, 23, 110-117.

Hidi, S., \& Renninger, K. A. (2006). The four-phase model of interest development. Educational Psychologist, 41, 111-127.

Hoffmann, L. (2002). Promoting girls' interest and achievement in physics classes for beginners. Learning and Instruction, 12, 447-465.

Hofstein, A., \& Lunetta, V. N. (2003). The laboratory in science education: foundations for the twenty-first century. Science Education, 88, 28-54.

Holstermann, N., \& Bögeholz, S. (2007). Interesse von Jungen und Mädchen an naturwissenschaftlichen Themen am Ende der Sekundarstufe I [Gender-specific interests of adolescent learners in science topics]. Zeitschrift für Didaktik der Naturwissenschaften, 13, 71-86.

Krapp, A. (2005). Basic needs and the development of interest and intrinsic motivational orientations. Learning and Instruction, 15, 381-395.

Löwe, B. (1992). Biologieunterricht und Schülerinteresse an Biologie [Biology education and students' interest in biology]. Weinheim: Deutscher Studienverlag.

Lumpe, A. T., \& Oliver, J. S. (1991). Dimensions of hands-on science. The American Biology Teacher, 53, 345-348.

Middleton, J. A. (1995). A study of intrinsic motivation in the mathematics classroom: a personal constructs approach. Journal for Research in Mathematics Education, 26, 254-279.

Moneta, G. B., \& Csikszentmihalyi, M. (1996). The effect of perceived challenges and skills on the quality of subjective experience. Journal of Personality, 64, 275-310.

National Association of Biology Teachers [NABT] (2005). Role of laboratory and field instruction in biology education. NABT Position Statement. Retrieved November 19, 2008, from http://www.nabt.org/sites/S1/ index.php?p=67

Nott, M., \& Wellington, J. (1996). When the black box springs open: practical work in schools and the nature of science. International Journal of Science Education, 18, 807-818.

Pekrun, R., Goetz, T., Titz, W., \& Perry, R. P. (2002). Academic emotions in students' self-regulated learning and achievement: a program of qualitative and quantitative research. Educational Psychologist, 37, 91-105.

Renner, J. W., Abraham, M. R., \& Birnie, H. H. (1985). Secondary school students' beliefs about the physics laboratory. Science Education, 69, 649-663.

Rheinberg, F., Vollmeyer, R., \& Rollett, W. (2000). Motivation and action in self-regulated learning. In M. Boekarts, P. R. Pintrich \& M. Zeidner (Eds.), Handbook of self-regulation (pp. 503-528). San Diego: Academic.

Rutherford, F. J. (1993). Hands-on: a means to an end. Project 2061 Today, 3. Retrieved June 13, 2008, from http://www.project2061.org/publications/2061Connections/archive.htm.

Schiefele, U. (1991). Interest, learning, and motivation. Educational Psychologist, 26, 299-323. 
Schiefele, U., Krapp, A., \& Schreyer, I. (1993). Metaanalyse des Zusammenhangs von Interesse und schulischer Leistung [Meta-analysis of the relationship between interest and academic achievement]. Zeitschrift für Entwicklungspsychologie und Pädagogische Psychologie, 25, 120-148.

Sjøberg, S., \& Schreiner, C. (2005). How do learners in different cultures relate to science and technology? Results and perspectives from the project ROSE (The Relevance of Science Education). Asia-Pacific Forum on Science Learning and Teaching, 6, 1-16.

Thompson, J., \& Soyibo, K. (2002). Effects of lecture, teacher demonstrations, discussions and practical work on 10th graders' attitudes to chemistry and understanding of electrolysis. Research in Science \& Technological Education, 20, 25-37.

Todt, E. (1995). Entwicklung des Interesses [Development of interest]. In H. Hetzer, E. Todt, I. SeiffgeKrenke \& R. Arbinger (Eds.), Angewandte Entwicklungspsychologie des Kindes- und Jugendalters (pp. 213-264). Heidelberg: Quelle \& Meyer.

Vogt, H., Upmeier zu Belzen, A., Schröer, T., \& Hoek, I. (1999). Unterrichtliche Aspekte im Fach Biologie, durch die Unterricht aus Schülersicht als interessanter erachtet wird. [Aspects of biology education which make biology classes more interesting from a students' perspective]. Zeitschrift für Didaktik der Naturwissenschaften, 5, 75-85. 